\title{
Comparative absorption, distribution, and excretion of titanium dioxide and zinc oxide nanoparticles after repeated oral administration
}

\author{
Wan-Seob Cho', Byeong-Cheol Kang ${ }^{2}$, Jong Kwon Lee ${ }^{3}$, Jayoung Jeong ${ }^{3}$, Jeong-Hwan Che ${ }^{2^{*+}}$ \\ and Seung Hyeok Seok ${ }^{4 *}$
}

\begin{abstract}
Background: The in vivo kinetics of nanoparticles is an essential to understand the hazard of nanoparticles. Here, the absorption, distribution, and excretion patterns of titanium dioxide $\left(\mathrm{TiO}_{2}\right)$ and zinc oxide $(\mathrm{ZnO})$ nanoparticles following oral administration were evaluated.

Methods: Nanoparticles were orally administered to rats for 13 weeks (7 days/week). Samples of blood, tissues (liver, kidneys, spleen, and brain), urine, and feces were obtained at necropsy. The level of Ti or Zn in each sample was measured using inductively coupled plasma-mass spectrometry.

Results: $\mathrm{TiO}_{2}$ nanoparticles had extremely low absorption, while $\mathrm{ZnO}$ nanoparticles had higher absorption and a clear dose-response curve. Tissue distribution data showed that $\mathrm{TiO}_{2}$ nanoparticles were not significantly increased in sampled organs, even in the group receiving the highest dose (1041.5 mg/kg body weight). In contrast, Zn concentrations in the liver and kidney were significantly increased compared with the vehicle control. ZnO nanoparticles in the spleen and brain were minimally increased. Ti concentrations were not significantly increased in the urine, while $\mathrm{Zn}$ levels were significantly increased in the urine, again with a clear dose-response curve. Very high concentrations of Ti were detected in the feces, while much less Zn was detected in the feces.

Conclusions: Compared with $\mathrm{TiO}_{2}$ nanoparticles, $\mathrm{ZnO}$ nanoparticles demonstrated higher absorption and more extensive organ distribution when administered orally. The higher absorption of $\mathrm{ZnO}$ than $\mathrm{TiO}_{2}$ nanoparticles might be due to the higher dissolution rate in acidic gastric fluid, although more thorough studies are needed.
\end{abstract}

Keywords: $\mathrm{TiO}_{2}, \mathrm{ZnO}$, Oral administration, Absorption, Distribution, Excretion

\section{Background}

Nanomaterials have been developed for the food industry for uses such as food storage, preventing microbial growth, and as a nutritional ingredient [1,2]. Titanium dioxide $\left(\mathrm{TiO}_{2}\right)$ and zinc oxide $(\mathrm{ZnO})$ have unique physicochemical properties including a bright white color, ability to block UV light, and antimicrobial activity. $\mathrm{TiO}_{2}$ nanoparticles naturally exist in three different

\footnotetext{
* Correspondence: casache@snu.ac.kr; lamseok@snu.ac.kr

${ }^{\dagger}$ Equal contributors

${ }^{2}$ Biomedical Research Institute, Seoul National University Hospital, Seoul 110-744, Republic of Korea

${ }^{4}$ Department of Microbiology and Immunology, and Institute of Endemic Disease, Seoul National University College of Medicine, Seoul 110-799, Republic of Korea

Full list of author information is available at the end of the article
}

crystalline structures (anatase, rutile and brookite) and have a high refractive index. $\mathrm{TiO}_{2}$ is widely used as a pigment (paint, plastics, and paper), in personal care products (sunscreen and toothpastes), and in food (cream) [3]. The bright white color of micron-sized $\mathrm{TiO}_{2}$ might be more useful for some applications than nanosized $\mathrm{TiO}_{2}$ because $\mathrm{TiO}_{2}$ becomes more transparent as its particle size decreases. However, smaller $\mathrm{TiO}_{2}$ particles have higher UV-blocking properties, which can be advantageous for food storage [4]. In addition, nanosized $\mathrm{TiO}_{2}$ prevents microbial growth [5]. Because of these properties, nanosized $\mathrm{TiO}_{2}$ might be popular in the food industry with further technological developments. $\mathrm{ZnO}$ is another commonly used particle with similar utility to $\mathrm{TiO}_{2}$. In addition, $\mathrm{ZnO}$ is used for its antimicrobial

\section{Biomed Central}


properties and in nutritional supplements such as multivitamins [6,7]. Compared with micron-sized $\mathrm{ZnO}$, nanosized $\mathrm{ZnO}$ might have better UV-blocking and antimicrobial properties and higher bioavailability [8].

The increased use of these particles might increase the possibility of human exposure through various routes such as inhalation, ingestion, and skin contact. In addition to uses for humans, nanomaterials are used with livestock and in the environment. $\mathrm{TiO}_{2}$ nanoparticles are generally considered to have low toxicity regardless of their size and crystallinity [9]. However, recent in vitro studies have reported that $\mathrm{TiO}_{2}$ nanoparticles are genotoxic through the production of reactive oxygen species [10,11], although in vitro studies have limited predictive value for in vivo situations. In contrast to $\mathrm{TiO}_{2}$ nanoparticles, $\mathrm{ZnO}$ nanoparticles are well known to have high toxicity. One of the mechanisms of this toxicity is their ionization in biological fluids [12].

Combined with toxicity data, kinetics data can provide the actual concentration of nanoparticles as they interact with biological systems. However, compared with other routes of administration, kinetics data following the oral administration of nanoparticles is limited. Humans have a higher chance of being exposed to $\mathrm{TiO}_{2}$ and $\mathrm{ZnO}$ nanoparticles in food-related products than other nanoparticles. Therefore, further evaluation of the tissue distribution and absorption of these nanoparticles following oral administration is needed to provide valuable information for assessing the risk of these nanoparticles. We selected $\mathrm{TiO}_{2}$ and $\mathrm{ZnO}$ to evaluate nanoparticle absorption, tissue distribution, and excretion following 13 weeks of repeated oral administration.

\section{Results}

Physicochemical characterization of nanoparticles

$\mathrm{TiO}_{2}$ nanoparticles were spherical and $\mathrm{ZnO}$ nanoparticles were hexagonal (Figure 1). Table 1 summarizes the physicochemical properties of the $\mathrm{TiO}_{2}$ and $\mathrm{ZnO}$ nanoparticles. The primary sizes of $\mathrm{TiO}_{2}$ nanoparticles provided by the manufacturer were similar to those measured by scanning electron microscopy (SEM) and dynamic light scattering (DLS), while $\mathrm{ZnO}$ nanoparticles sizes differed significantly by the two measurement type. The hydrodynamic size of the $\mathrm{ZnO}$ nanoparticles suggested that $\mathrm{ZnO}$ formed small aggregates when dispersed in distilled water (DW). $\mathrm{TiO}_{2}$ nanoparticles had sizes similar to the primary particle size. No particles showed endotoxin contamination. The zeta potential of the $\mathrm{TiO}_{2}$ nanoparticles was $54.4 \pm 0.7 \mathrm{mV}$ for $\mathrm{pH} 2$ and $7.9 \pm 2.7 \mathrm{mV}$ for $\mathrm{pH}$ 8. The zeta potential of $\mathrm{ZnO}$ was more negative than $\mathrm{TiO}_{2}$, at $11.7 \pm 0.8 \mathrm{mV}$ for $\mathrm{pH} 2$ and $-25.1 \pm 2.6 \mathrm{mV}$ for $\mathrm{pH} 8$.

\section{Durability of nanoparticles under biological conditions}

$\mathrm{TiO}_{2}$ nanoparticles showed minimal dissolution in both acidic gastric fluid (AGF) and pH 7.4 conditions (Figure 2A). However, $\mathrm{ZnO}$ nanoparticles dissolved in AGF within five minutes. In basic conditions, $\mathrm{ZnO}$ showed minimal dissolution after monitoring for up to $24 \mathrm{~h}$. This dissolution
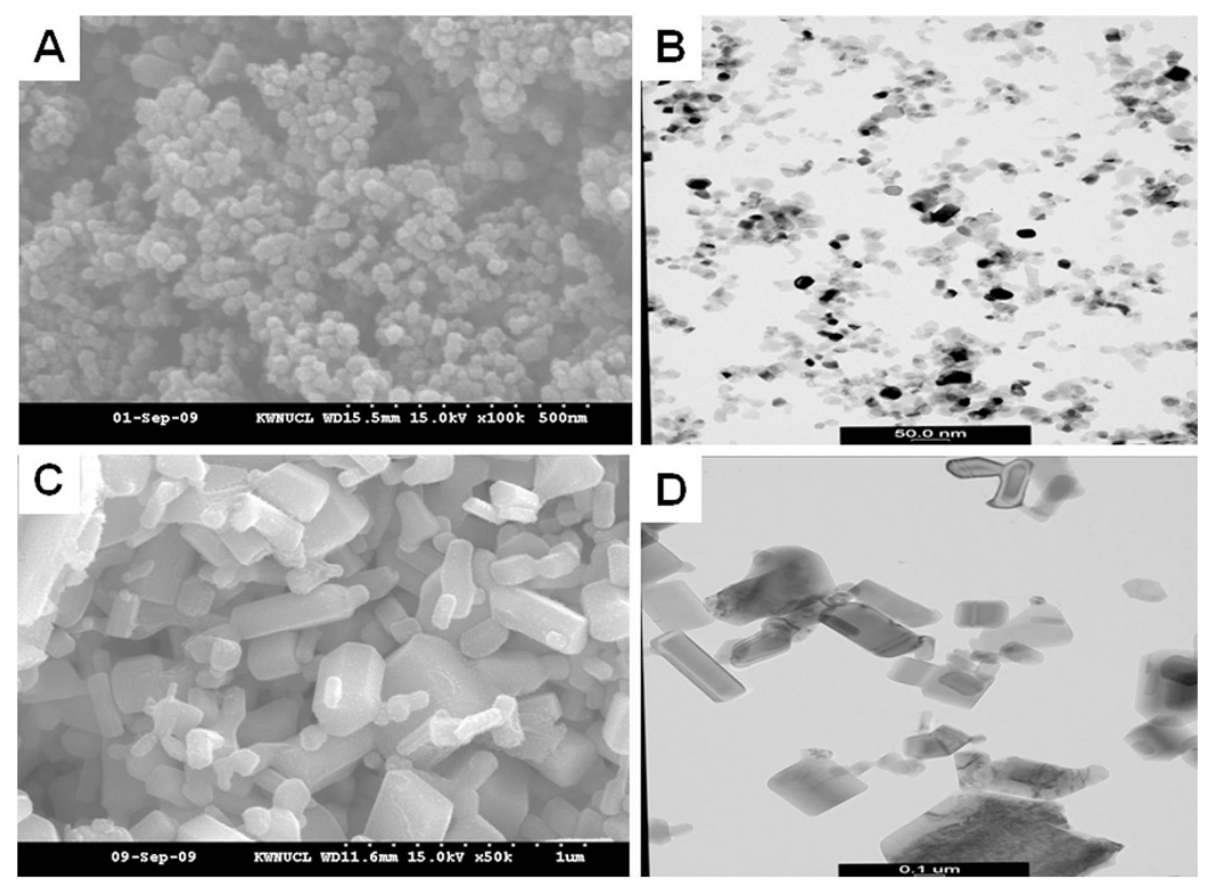

Figure 1 SEM and TEM of $\mathrm{TiO}_{2}$ and $\mathrm{ZnO}$ nanoparticles. SEM (A) and TEM (B) images of $\mathrm{TiO}_{2}$ nanoparticles show spherical shape. SEM (C) and TEM (D) images of ZnO nanoparticles show hexagonal shape. 
Table 1 Physicochemical characterization of metal oxide nanoparticles

\begin{tabular}{|c|c|c|c|c|c|c|}
\hline \multirow[t]{2}{*}{ Particles } & \multirow[t]{2}{*}{ Crystallinity } & \multicolumn{2}{|c|}{ Primary size $(\mathrm{nm})$ measured by } & \multirow{2}{*}{$\begin{array}{l}\text { Hydrodynamic } \\
\text { size }(\mathrm{nm})^{\mathrm{a}}\end{array}$} & \multirow{2}{*}{$\begin{array}{c}\text { Surface } \\
\text { area }\left(\mathrm{m}^{2} / \mathrm{g}\right)^{\mathrm{b}}\end{array}$} & \multirow{2}{*}{$\begin{array}{c}\text { Endotoxin } \\
(\mathrm{pg} / \mathrm{ml})^{c}\end{array}$} \\
\hline & & Manufacturer & SEM & & & \\
\hline $\mathrm{TiO}_{2}$ & Anatase 80: 20 Rutile & 21 & $26.4 \pm 6.1$ & $37.8 \pm 0.4$ & $50 \pm 15$ & N.D. \\
\hline $\mathrm{ZnO}$ & Hexagonal & 40 & $89.3 \pm 44.7$ & $201.8 \pm 17.2$ & $60 \pm 10$ & N.D. \\
\hline
\end{tabular}

ND not detectable. SEM scanning electron microscopy.

${ }^{a}$ Nanoparticles were dispersed in DW and measured by a dynamic light scattering method.

${ }^{b}$ Specific surface area by the Brunauer-Emmett-Teller method was provided by the manufacturer.

'Levels of endotoxin were measured using an Endpoint Chromogenic Limulus Amebocyte Lysate assay (Cambrex, MD, USA).

pattern was confirmed by an inductively coupled plasmamass spectrometry (ICP-MS) (Figure 2B).

\section{Body weight changes}

When nanoparticles were administered for consecutive 13-week to female Sprague-Dawley rats, the body weight of given a high dose of $\mathrm{ZnO}$ nanoparticles was significantly lower than animals given in the vehicle control (Additional file 1: Tables S1-S4). However, other ZnOtreatment groups and the $\mathrm{TiO}_{2}$ nanoparticle-treatment groups showed no significant changes compared with the vehicle-control group.

\section{Absorption of nanoparticles}

The concentrations of $\mathrm{Zn}$ in the blood of the $\mathrm{ZnO}$ treatment groups demonstrated a clear dose-response relationship (Figure 3). However, the concentrations of $\mathrm{Ti}$ in the male $\mathrm{TiO}_{2}$-treatment groups showed a less steep slope in the dose-response relationship. Female rats treated with $\mathrm{TiO}_{2}$ showed no dose-response relationship for blood concentration. The $\mathrm{Zn}$ blood concentration in the $\mathrm{ZnO}$ treatment groups was almost 10-fold higher than the $\mathrm{Ti}$ concentration in the $\mathrm{TiO}_{2}$-treatment groups.

\section{Distribution of nanoparticles}

The distribution patterns of $\mathrm{Ti}$ and $\mathrm{Zn}$ in the liver, spleen, kidney, and brain after 13 weeks of repeated oral administration of $\mathrm{TiO}_{2}$ or $\mathrm{ZnO}$ nanoparticles were measured using ICP-MS. Ti concentrations in the $\mathrm{TiO}_{2}$-treatment groups showed no significant increase in the sampled organs compared with the vehicle control group (Figure 4 and Additional file 2: Figure S1). The $\mathrm{Zn}$ concentration in the liver and kidney showed a significant increase in the highest dose group with a positive, dose-related trend (Figure 5 and Additional file 2: Figure S2). In addition, the concentration of $\mathrm{Zn}$ in liver and kidney was much higher than in the spleen and brain. In spleen and brain tissue, the Zn concentration showed no dose-related response compared with the vehicle control, even in the high-dose group.

\section{Excretion of nanoparticles}

The urine concentration of $\mathrm{Ti}$ in the $\mathrm{TiO}_{2}$-treatment groups showed no significant differences compared with the control group, which was consistent with the tissue distribution patterns (Figure 6A). In contrast, the concentration of $\mathrm{Zn}$ in the urine of $\mathrm{ZnO}$-treatment groups was significantly increased in the middle- and high-dose groups and showed positive trend dose-responses (Figure $6 \mathrm{C}$ ). $\mathrm{Ti}$ or $\mathrm{Zn}$ concentrations in the feces were very high compared to concentrations in the urine or tissues, with clear dose responses. These results suggested that most of the nanoparticles were not absorbed from the gastrointestinal lumen (Figures 6B and 6D).

\section{Discussion}

$\mathrm{TiO}_{2}$ and $\mathrm{ZnO}$ particles are widely used as ingredients and food supplements [3,6,7]. As nanotechnology develops, these traditional materials have also been applied
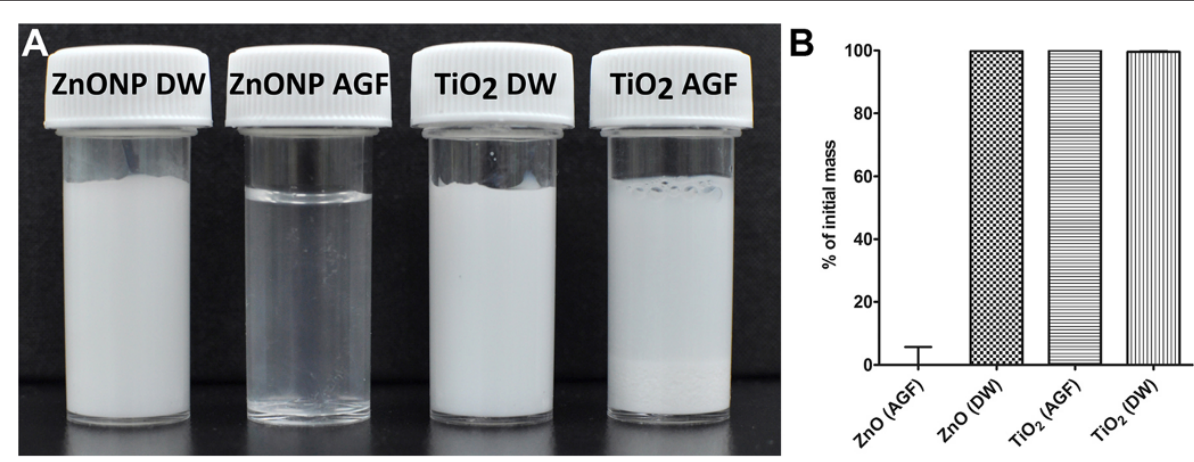

Figure 2 Dissolution pattern of nanoparticles in the acidic gastric fluid. AGF, pH 1.5; basic condition, DW, pH 7.4. Nanoparticles were incubated with AGF or DW for up to 24 h. (A) Image taken 5 min after incubation using a digital camera. (B) Percentage of dissolution measured using an ICP-MS at $24 \mathrm{~h}$ after incubation. 

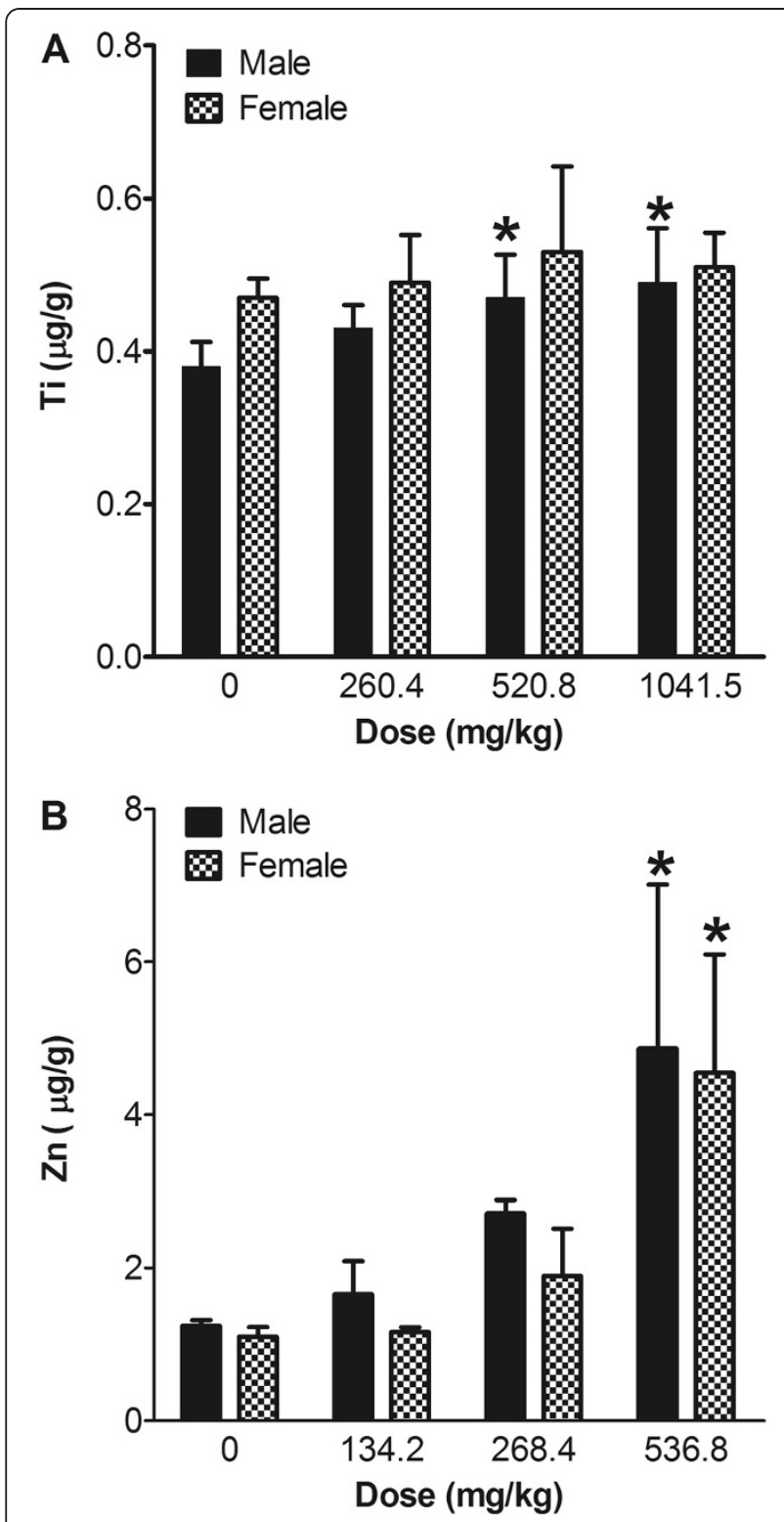

Figure 3 Systemic absorption of nanoparticles from the gastrointestinal tract after 13 weeks of repeated oral treatment. Ti concentration in whole blood (A) showed about a 10fold lower absorption than Zn concentration in whole blood (B) in both sexes. Values are mean \pm S.D. and $n=11$. Significance versus vehicle control: ${ }^{*} p<0.05$.

in nanoparticulate form. However, nanoparticles interact with biological systems through different mechanisms of action than bulk chemicals [13]. Nanoparticles are considered to be more highly absorbed into the respiratory, skin, and gastrointestinal systems than micron-sized particles because of their unique physicochemical properties, such as their size and surface modifications [14]. For example, instillation of $5 \mathrm{~nm}$ fluorescent nanoparticles shows faster translocation to other organs than $27 \mathrm{~nm}$ nanoparticles [15]. In addition, a recent study showed that only nanoparticles were translocated into the circulation system when administered into the lung; their absorption rate varied, depending on their surface properties [16]. The uptake of particles into skin cells was observed to be size dependent [17]. When different sizes of polystyrene particles were administered orally to rats, the absorption of 50-100 nm polystyrene nanoparticles was about 250-fold higher than absorption of larger microparticles $(500 \mathrm{~nm}$, 1 , and $10 \mu \mathrm{m})[18,19]$. Oral administration of different sizes of colloidal gold particles to mice showed sizedependent absorption [20]. Regarding surface modification, positively charged particles show better absorption than neutral or negatively charged particles [21]. However, in a recent study using gold nanoparticles, negatively charged particles showed higher absorption rates than positively charged particles [22]. Therefore, no general rule can be made about absorption from these results and further studies are needed on the impact of surface modification on gastrointestinal absorption. Studying the kinetics of nanoparticles is an important issue in nanotechnology. Compared with inhalation or skin exposure, the oral intake of nanoparticles in food-related settings has the potential for wide exposure of the public to higher doses and more frequent ingestion $[1,2]$. This study focused on the kinetics of the nano-particulate forms of $\mathrm{TiO}_{2}$ and $\mathrm{ZnO}$ as representative food-related nanomaterials.

Both particle types showed very low absorption although the exact absorption rate could not be calculated. The concentration of $\mathrm{Ti}$ in the blood samples of rats treated with $\mathrm{TiO}_{2}$ for 13 weeks was $0.4-0.5 \mu \mathrm{g} / \mathrm{g}$ and the differences between the values of the control and highdose groups were less than $0.1 \mu \mathrm{g} / \mathrm{g}$. Considering that the dose for the high-dose group was $1041.5 \mathrm{mg} / \mathrm{kg}$ body weight, $\mathrm{TiO}_{2}$ nanoparticles might have an extremely low absorption rate, although additional experiments are needed to confirm this. In contrast, the $\mathrm{Zn}$ concentration in the blood of rats in the $\mathrm{ZnO}$-treatment groups showed an almost 10-fold higher dose and a steeper dose-response curve than values for animals in the $\mathrm{Ti}$ groups. The higher concentration of $\mathrm{Zn}$ in blood compared to $\mathrm{Ti}$ might be because of the biopersistence of nanoparticles. $\mathrm{TiO}_{2}$ and $\mathrm{ZnO}$ nanoparticles have different durability under acidic conditions, although both are minimally destructive in basic or physiological conditions. In our previous study, $\mathrm{ZnO}$ nanoparticles showed rapid dissolution in acidic conditions ( $\mathrm{pH} 5.5$ ) [12,23]. Because the $\mathrm{pH}$ of the gastric fluid is between 1.5 and 2.0, $\mathrm{ZnO}$ nanoparticles administered orally must dissolve in the stomach, with $\mathrm{Zn}$ ions then absorbed to enter into systemic circulation. In contrast, the low absorption rate of $\mathrm{TiO}_{2}$ might be because of their low solubility. The low absorption after oral administration of nanoparticles is consistent with the micron-sized biocompatible $\mathrm{TiO}_{2}$ particles [24]. Low absorption would be favorable from a 

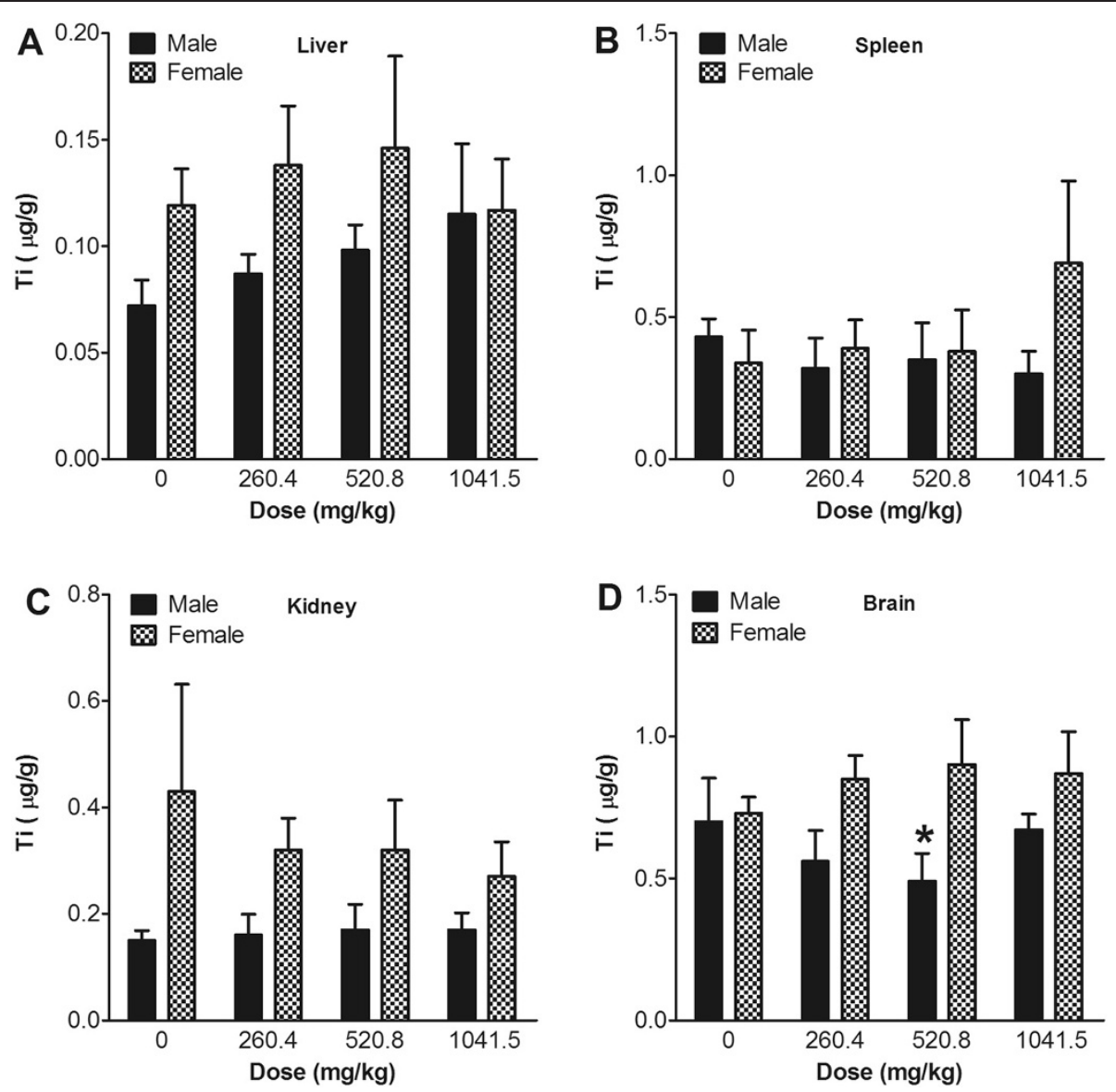

Figure 4 Concentration of $\mathrm{Ti}$ in tissues after 13 weeks of consecutive oral administration of $\mathrm{TiO}_{2}$ nanoparticles. The concentrations of $\mathrm{Ti}$ in the liver (A), spleen (B), kidney (C), and brain (D) were evaluated using an ICP-MS. Values are mean \pm S.D. and $n=11$. Significance versus vehicle control: ${ }^{*} p<0.05$.

risk perspective, especially in non-nutritional applications of nanoparticles such as in food preparation, handling, storage, and prevention of microbial growth. However, even with marginal absorption, some absorbed nanoparticles might pose a risk based on their toxic potential.

$\mathrm{TiO}_{2}$ distribution to the liver, spleen, kidney, and brain was also minimal. No dose-response relationship was seen, meaning that the $\mathrm{TiO}_{2}$ particles were not significantly distributed. This low distribution was due to the minimal absorption rate. This result was in contrast with a previous study that observed systemic translocation of $\mathrm{TiO}_{2}$ nanoparticles through the gastrointestinal tract [3]. Therefore, further studies and advanced methods to detect nanoparticles in the tissues are warranted. However, $\mathrm{ZnO}$ nanoparticles showed significant levels of $\mathrm{Zn}$ in the tested organs, particularly in the liver and kidney, with steep dose-response curves. In a previous study, orally administered $\mathrm{ZnO}$ nanoparticles were mainly distributed to the liver and kidney within $72 \mathrm{~h}$ following administration [25,26]. When two different sizes of $\mathrm{ZnO}$ were administered, the particle size and gender of animals did not influence the tissue distribution pattern [25]. In addition, orally administered zinc-65 was mainly distributed in the liver, muscle, lung, kidneys, and bone [27].

Data on the excretion of the nanoparticles were consistent with the absorption and distribution patterns. The Ti concentration in urine showed no significant differences from the controls, while the $\mathrm{Zn}$ concentration in urine was significantly higher than the vehicle controls, with clear dose-responses. $\mathrm{ZnO}$ nanoparticles administered orally are excreted via the urine [25]. The main routes of elimination of nanoparticles are urine/kidney and bile/ liver. Renal excretion was confirmed in several studies using a multi-walled carbon nanotube [28] and quantum dots [29]. However, studies using quantum dots [30,31] and gold nanoparticles [32] showed long-term accumulation in the organs and no or minimal excretion via urine. 

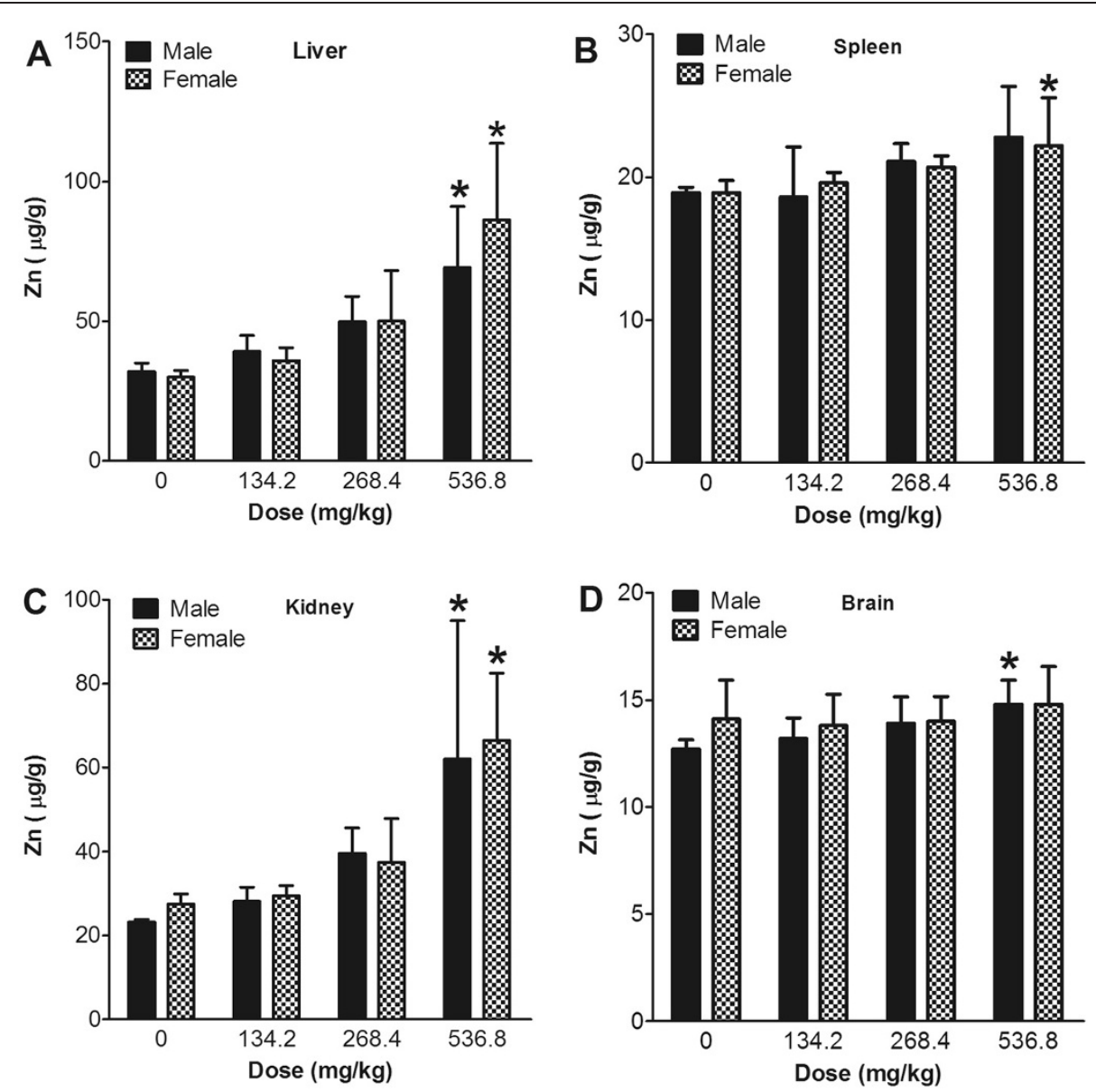

Figure 5 Concentration of $\mathrm{Zn}$ in tissues after 13 weeks of consecutive oral administration of $\mathrm{ZnO}$ nanoparticles. The concentrations of $\mathrm{Zn}$ in the liver (A), spleen (B), kidney (C), and brain (D) were evaluated using an ICP-MS. Values are mean \pm S.D. and $n=11$. Significance versus vehicle control: ${ }^{*} p<0.05$.

The number of nanoparticle elimination study is relatively limited and further studies are warranted.

\section{Conclusions}

Zinc concentrations in blood, organs, and urine were higher than concentrations of titanium when nanoparticles were administered orally for 13 weeks. The kinetics of nanoparticles via oral administration might be influenced by interactions between the physicochemical properties of nanoparticles and the biological milieu with which they come into contact. The low absorption of $\mathrm{TiO}_{2}$ and $\mathrm{ZnO}$ nanoparticles might be favorable, especially for nonnutritional applications. More thorough instigations regarding the impact of physicochemical properties on the kinetics of nanoparticles are warranted.

\section{Methods}

Nanoparticles and physicochemical characterization Powder-form $\mathrm{TiO}_{2}$ nanoparticles were obtained from ABC Nanotech Co., Ltd. (Daejeon, Korea). Well-dispersed
$\mathrm{ZnO}$ nanoparticles at $20 \mathrm{wt} \%$ in distilled water (DW) were obtained from Nanostructured and Amorphous Materials, Inc. (TX, USA). Primary particle sizes and morphology were measured using scanning electron microscopy (S-3500 N, Hitachi Science Systems, Ltd., Japan) and transmission electron microscopy (LEO-912AB Omega, LEO, Japan). The hydrodynamic size and zeta potential of nanoparticles in DW were measured using a DelsaNano (Beckman Coulter, Inc., CA, USA) according to the manufacturer's instructions. Briefly, the optimal concentration of $\mathrm{TiO}_{2}$ and $\mathrm{ZnO}$ for measurement was screened by serial dilution under following conditions: temperature $25^{\circ} \mathrm{C}$, refractive index 1.33 , scattering angle $165^{\circ}$, laser wavelength $632.8 \mathrm{~nm}$. The zeta potential of nanoparticles was measured under acidic conditions $(\mathrm{pH} 2.0)$ to simulate acidic gastric conditions, and under basic conditions ( $\mathrm{pH}$ 8.0) to simulate the small intestine. Levels of endotoxin contamination were measured using an Endpoint Chromogenic Limulus Amebocyte Lysate assay (Cambrex, MD, USA). 

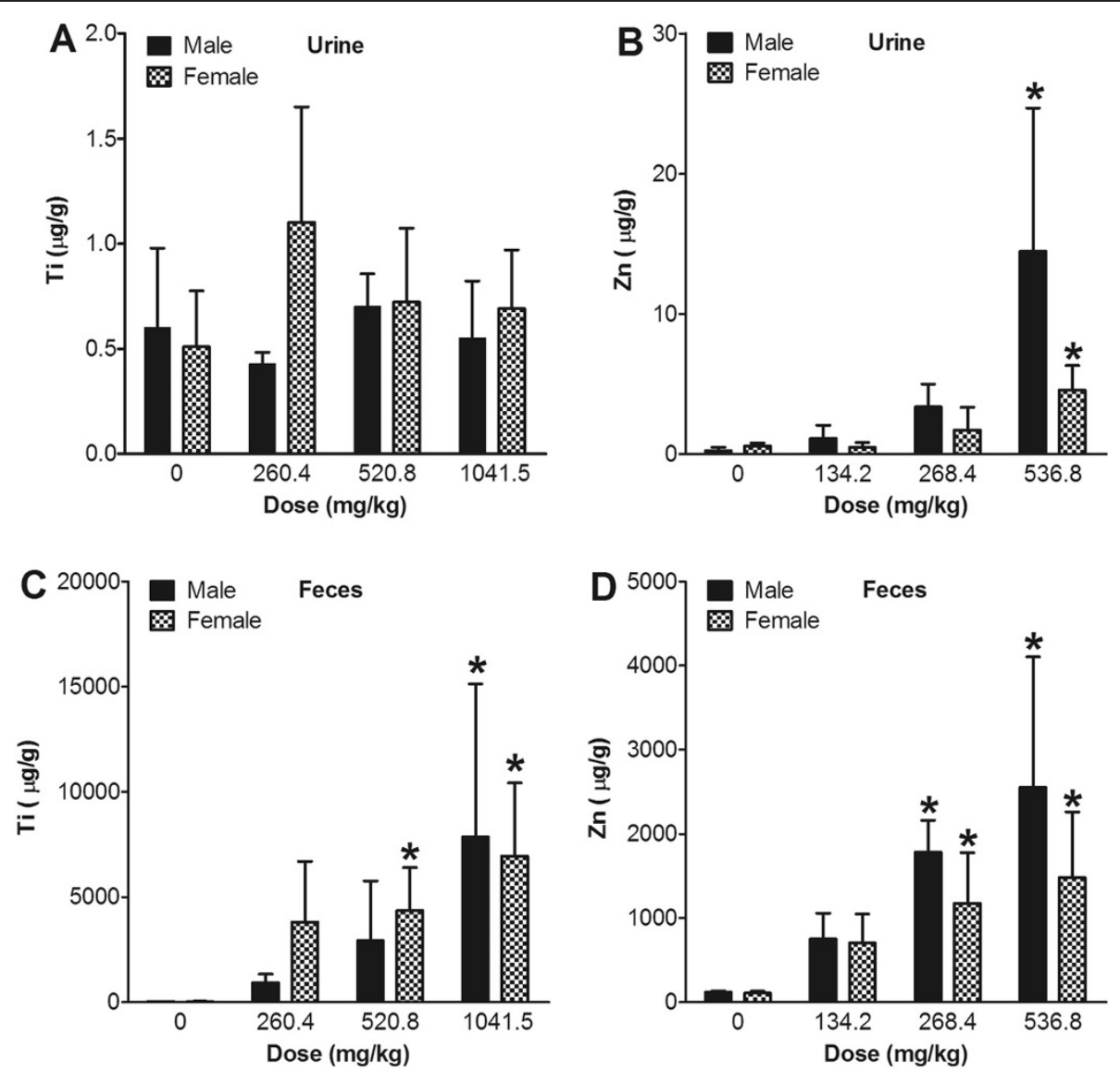

Figure 6 Excretion of nanoparticles after 13 weeks of consecutive oral administration. The concentrations of Ti in urine (A) and feces (C) were measured using an ICP-MS for $\mathrm{TiO}_{2}$ treatment groups. The concentrations of $\mathrm{Zn}$ in urine (B) and feces (D) were measured using an ICP-MS for $\mathrm{ZnO}$ treatment groups. Values are mean \pm S.D. and $n=11$. Significance versus vehicle control: ${ }^{*} p<0.05$.

\section{Durability of nanoparticles in biological conditions}

$\mathrm{TiO}_{2}$ and $\mathrm{ZnO}$ nanoparticles were incubated with acidic gastric fluid (AGF, pH 1.5-2.0) or under basic conditions (pH 7.4). AGF was prepared according to a previously described method [33]. Briefly, $2.0 \mathrm{~g} \mathrm{NaCl}$ (SigmaAldrich, St. Louis Mo. USA) and 3.2 g pepsin (SigmaAldrich) were dissolved in $1 \mathrm{~L}$ of $\mathrm{DW}$ and the $\mathrm{pH}$ was adjusted to 1.5 using $2 \mathrm{~N} \mathrm{HCl}$ (Sigma-Aldrich). DW at $\mathrm{pH} 7.4$ was used for the basic solution. Nanoparticles at $5 \mathrm{mg} / \mathrm{mL}$ were incubated in solution for up to $24 \mathrm{~h}$. The degree of ionization was evaluated at $24 \mathrm{~h}$ postincubation using inductively coupled plasma-mass spectrometry (ICP-MS). Briefly, at $24 \mathrm{~h}$ after incubation in solution, nanoparticle-free supernatants were collected by three rounds of centrifugation at $15000 \times g$ for $30 \mathrm{~min}$. The concentrations of zinc or titanium were measured using ICP-MS (X7; Thermo Elemental, Winsford, UK) as previously described method [34]. Gross images were taken using a digital camera (Nikon Corp., Tokyo, Japan).

\section{Animal handling and protocols}

Six-week-old specific-pathogen free Sprague-Dawley rats were obtained from OrientBio Ltd. (Seongnam, Korea) and acclimated for seven days after arrival at the study facility. Rodents were housed in an animal room at a controlled temperature $\left(21-24^{\circ} \mathrm{C}\right)$, humidity $(45-60 \%)$, and light cycle (12 h light/dark). Autoclaved water and gamma-irradiated rodent diets (LabDiet 5002, PMI nutrition, Richmond, USA) were provided ad libitum. The concentration of zinc in the diet was $74 \pm 7.1 \mathrm{ppm}$ as provided by the manufacturer (PMI Nutrition, Richmond, USA) and was not detectable in water provided by the Office of Waterworks (Seoul Metropolitan Government, Seoul, Korea). The concentrations of titanium in the diet and water were not known. All animal experiments were performed according to the Organization for Economic Co-operation and Development test guideline (TG 408) and the Good Laboratory Practices for toxicity test guidance (Notification No. 2005-60, Oct. 21, 2005) issued by the Korea Food and Drug 
Administration. Animal experiment protocols were approved by the Animal Care and Use Committee of Seoul National University Hospital, Korea.

\section{Dose-range finding study for 13 weeks of repeated oral nanoparticle administration}

A single-dose acute toxicity study and a 14-day repeated toxicity study of the oral route were performed. For the 14-day study, $\mathrm{TiO}_{2}$ was administered orally at 520.8, 1041.5 , and $2083 \mathrm{mg} / \mathrm{kg} /$ day, and $\mathrm{ZnO}$ was administered at $536.8,1073.5$, and $2147 \mathrm{mg} / \mathrm{kg} /$ day. Survival, clinical signs, body weight change, hematological change, serum biochemical change, organ weight, and necropsy findings were evaluated for MTD endpoints. There were no treatment-related findings in the $\mathrm{TiO}_{2}$ study; the highest dose over 13 weeks was selected as $1041.5 \mathrm{mg} / \mathrm{kg} /$ day for studying long-term exposure. For $\mathrm{ZnO}$, clinical signs (erection of fur, depression, abdominal inflation, and diarrhea) and a more than $10 \%$ reduction of body weight were observed at doses over $1073.5 \mathrm{mg} / \mathrm{kg}$ in both sexes. Several hematological parameters and the level of alkaline phosphatase were significantly differed than in the vehicle control (data not shown). Based on these data, the maximum tolerated dose (MTD) was determined to be 1041.5 for $\mathrm{TiO}_{2}$ and 536.8 for $\mathrm{ZnO}$ nanoparticles.

\section{3-week repeated oral administration of nanoparticles}

Eleven rats were assigned to each of four treatment groups: vehicle control (DW), $\mathrm{ZnO}$ nanoparticles at 134.2, 268.4, and $536.8 \mathrm{mg} / \mathrm{kg} / \mathrm{day}$, and $\mathrm{TiO}_{2}$ nanoparticles at 260.4, 520.8, and $1041.5 \mathrm{mg} / \mathrm{kg} /$ day. All nanoparticles were suspended in DW at each working concentration and orally administered at $10 \mathrm{ml} / \mathrm{kg}$ body weight according to the Handbook of Toxicology, second edition [35]. Administration volume was adjusted based on body weight measured each week. Each group was treated with same concentration of nanoparticles for the entire 13 weeks. Oral administration was done 7 days per week without any anesthesia or starvation. Animals were weighed weekly and observed daily for clinical signs and mortality. Animals were sacrificed and dissected one day after final gavage.

\section{Absorption, distribution, and excretion of nanoparticles}

Blood was taken via the abdominal vein at necropsy followed by isoflurane euthanization. To evaluate tissue distribution, tissue samples from the liver, spleen, kidney, and brain were obtained and weighed. Nanoparticles excretion was tested in urine and feces. To collect urine and feces, five animals from each group were randomly assigned to a metabolic cage immediately after gavage, and urine and feces samples were collected for $24 \mathrm{~h}$. All samples were analyzed for elemental zinc and titanium to represent $\mathrm{ZnO}$ and $\mathrm{TiO}_{2}$ concentrations. ICP-MS was used to analyze zinc and titanium concentrations in samples as previously described [34]. The detection limit of ICP-MS was $0.1-1 \mathrm{ng} / \mathrm{L}$ for Ti and $0.1-10 \mathrm{ng} / \mathrm{L}$ for $\mathrm{Zn}$.

\section{Statistical analysis}

ICP-MS data were analyzed using one-way ANOVA (JMP ver. 4.0, NC, USA). Animal data were analyzed using TDMS ver 4.0 (KFDA, Osong, Korea). When statistically significant differences were indicated $(p<0.05)$, a Dunnett's $t$-test was employed for comparisons between the control and treatment groups.

\section{Additional files}

Additional file 1: Table S1. Body weight changes of male SD rats treated with $\mathrm{TiO} 2$ nanoparticles for 13 weeks. Table S2. Body weight changes of female SD rats treated with $\mathrm{TiO} 2$ nanoparticles for 13 weeks. Table S3. Body weight changes of male SD rats treated with $\mathrm{ZnO}$ nanoparticles for 13 weeks. Table S4. Body weight changes of female SD rats treated with $\mathrm{ZnO}$ nanoparticles for 13 weeks.

Additional file 2: Figure S1. Total concentrations of Ti per organs after 13 weeks of consecutive oral administration of $\mathrm{TiO}_{2}$ nanoparticles. Values are mean \pm S.D. and $n=11$. Significance versus vehicle control: ${ }^{*} p<0.05$. Figure S2. Total concentrations of Zn per organs after 13 weeks of consecutive oral administration of $\mathrm{ZnO}$ nanoparticles. Values are mean \pm S.D. and $n=11$. Significance versus vehicle control: ${ }^{*} p<0.05$.

Competing interests

The authors declare that they have no competing financial interests.

\section{Authors' contributions}

WSC, JHC and SHS provided key intellectual input in the conception and design of these studies, performed experiment, and aided in the writing of this manuscript. BCK provided expertise for kinetics data and contributed to the writing of the manuscript. JKL and JJ performed dissolution studies and contributed to the writing of the manuscript. All authors read and approved the final manuscript.

\section{Acknowledgements}

We gratefully acknowledge the financial support provided by the Korea Food and Drug Administration (09152KFDA700, 13182KFDA606) and the Ministry of Education, Science and Technology (2010-0004090).

\section{Author details}

'Department of Medicinal Biotechnology, College of Natural Resources and Life Science, Dong-A University, Busan 604-714, Republic of Korea.

${ }^{2}$ Biomedical Research Institute, Seoul National University Hospital, Seoul 110-744, Republic of Korea. ${ }^{3}$ Department of Toxicological Research, National Institute of Food and Drug Safety Evaluation, Korea Food and Drug Administration, Osong 363-700, Republic of Korea. ${ }^{4}$ Department of Microbiology and Immunology, and Institute of Endemic Disease, Seoul National University College of Medicine, Seoul 110-799, Republic of Korea.

Received: 18 October 2012 Accepted: 15 March 2013

Published: 26 March 2013

\section{References}

1. Rashidi L, Khosravi-Darani K: The applications of nanotechnology in food industry. Crit Rev Food Sci Nutr 2011, 51(8):723-730.

2. Chun AL: Will the public swallow nanofood? Nat Nanotechnol 2009, 4(12):790-791

3. Wang J, Zhou G, Chen C, Yu H, Wang T, Ma Y, Jia G, Gao Y, Li B, Sun J, et al: Acute toxicity and biodistribution of different sized titanium dioxide particles in mice after oral administration. Toxicol Lett 2007, 168(2):176-185.

4. Lin CC, Lin WJ: Sun protection factor analysis of sunscreens containing titanium dioxide nanoparticles. J Food Drug Anal 2011, 19(1):1-8. 
5. Ge Y, Schimel JP, Holden PA: Identification of soil bacteria susceptible to TiO2 and ZnO nanoparticles. App/ Environ Microbio/ 2012, 78(18):6749-6758.

6. Wiking $L$, Larsen $T$, Sehested J: Transfer of dietary zinc and fat to milkevaluation of milk fat quality, milk fat precursors, and mastitis indicators. J Dairy Sci 2008, 91(4):1544-1551.

7. Rincker MJ, Hill GM, Link JE, Meyer AM, Rowntree JE: Effects of dietary zinc and iron supplementation on mineral excretion, body composition, and mineral status of nursery pigs. J Anim Sci 2005, 83(12):2762-2774.

8. Teow Y, Asharani PV, Hande MP, Valiyaveettil S: Health impact and safety of engineered nanomaterials. Chem Commun (Camb) 2011, 47(25):7025-7038.

9. Rushton EK, Jiang J, Leonard SS, Eberly S, Castranova V, Biswas P, Elder A, Han X, Gelein R, Finkelstein J, et al: Concept of assessing nanoparticle hazards considering nanoparticle dosemetric and chemical/biological response metrics. J Toxicol Environ Health A 2010, 73(5):445-461.

10. Bhattacharya K, Davoren M, Boertz J, Schins RP, Hoffmann E, Dopp E: Titanium dioxide nanoparticles induce oxidative stress and DNA-adduct formation but not DNA-breakage in human lung cells. Part Fibre Toxicol 2009, 6:17.

11. Kermanizadeh A, Gaiser BK, Hutchison GR, Stone V: An in vitro liver model - assessing oxidative stress and genotoxicity following exposure of hepatocytes to a panel of engineered nanomaterials. Part Fibre Toxicol 2012, 9(1):28.

12. Cho WS, Duffin R, Howie SE, Scotton CJ, Wallace WA, Macnee W, Bradley M, Megson IL, Donaldson K: Progressive severe lung injury by zinc oxide nanoparticles; the role of $\mathrm{Zn} 2+$ dissolution inside lysosomes. Part Fibre Toxicol 2011, 8(1):27.

13. Oberdorster G, Oberdorster E, Oberdorster J: Nanotoxicology: an emerging discipline evolving from studies of ultrafine particles. Environ Health Perspect 2005, 113(7):823-839.

14. Fubini B, Ghiazza M, Fenoglio I: Physico-chemical features of engineered nanoparticles relevant to their toxicity. Nanotoxicology 2010, 4:347-363.

15. Choi HS, Ashitate Y, Lee JH, Kim SH, Matsui A, Insin N, Bawendi MG, Semmler-Behnke M, Frangioni JV, Tsuda A: Rapid translocation of nanoparticles from the lung airspaces to the body. Nat Biotechnol 2010, 28(12):1300-1303.

16. Kreyling WG, Semmler-Behnke M, Takenaka S, Moller W: Differences in the Biokinetics of Inhaled Nano- versus Micrometer-Sized Particles. Acc Chem Res. in press.

17. Rancan F, Gao Q, Graf C, Troppens S, Hadam S, Hackbarth S, Kembuan C, Blume-Peytavi U, Ruhl E, Lademann J, et al: Skin penetration and cellular uptake of amorphous silica nanoparticles with variable size, surface functionalization, and colloidal stability. ACS Nano 2012, 6(8):6829-6842.

18. Jani P, Halbert GW, Langridge J, Florence AT: The uptake and translocation of latex nanospheres and microspheres after oral administration to rats. J Pharm Pharmacol 1989, 41(12):809-812.

19. Jani P, Halbert GW, Langridge J, Florence AT: Nanoparticle uptake by the rat gastrointestinal mucosa: quantitation and particle size dependency. J Pharm Pharmacol 1990, 42(12):821-826.

20. Hillyer JF, Albrecht RM: Gastrointestinal persorption and tissue distribution of differently sized colloidal gold nanoparticles. J Pharm Sci 2001, 90(12):1927-1936.

21. Florence AT: Nanoparticle uptake by the oral route: fulfilling its potential? Drug Discovery Today: Technologies 2005, 2(1):75-81.

22. Schleh C, Semmler-Behnke M, Lipka J, Wenk A, Hirn S, Schaffler M, Schmid G, Simon U, Kreyling WG: Size and surface charge of gold nanoparticles determine absorption across intestinal barriers and accumulation in secondary target organs after oral administration. Nanotoxicology 2012, 6(1):36-46.

23. Cho WS, Duffin R, Thielbeer F, Bradley M, Megson IL, Macnee W, Poland CA, Tran CL, Donaldson K: Zeta potential and solubility to toxic ions as mechanisms of lung inflammation caused by metal/metal oxide nanoparticles. Toxicol Sci 2012, 126(2):469-477.

24. Abe S, Koyama C, Esaki M, Akasaka T, Uo M, Kuboki Y, Morita M, Watari F: In vivo internal diffusion of several inorganic microparticles through ora administration. Bio-Med Mater Eng 2009, 19(2-3):221-229.

25. Baek $M$, Chung HE, Yu J, Lee JA, Kim TH, Oh JM, Lee WJ, Paek SM, Lee JK, Jeong J, et al: Pharmacokinetics, tissue distribution, and excretion of zinc oxide nanoparticles. Int J Nanomedicine 2012, 7:3081-3097.

26. Lee CM, Jeong HJ, Yun KN, Kim DW, Sohn MH, Lee JK, Jeong J, Lim ST: Optical imaging to trace near infrared fluorescent zinc oxide nanoparticles following oral exposure. Int J Nanomedicine 2012, 7:3203-3209.
27. He LS, Yan XS, Wu DC: Age-dependent variation of zinc- 65 metabolism in LACA mice. Int J Radiat Biol 1991, 60(6):907-916.

28. Lacerda L, Soundararajan A, Singh R, Pastorin G, Al-Jamal KT, Turton J, Frederik P, Herrero MA, Li S, Bao A, et al: Dynamic imaging of functionalized multi-walled carbon nanotube systemic circulation and urinary excretion. Adv Mater 2008, 20(2):225-230.

29. Choi HS, Liu W, Misra P, Tanaka E, Zimmer JP, Itty Ipe B, Bawendi MG, Frangioni JV: Renal clearance of quantum dots. Nat Biotechnol 2007, 25(10):1165-1170.

30. Fischer HC, Liu L, Pang KS, Chan WCW: Pharmacokinetics of nanoscale quantum dots: in vivo distribution, sequestration, and clearance in the rat. Adv Funct Mater 2006, 16(10):1299-1305

31. Yang RS, Chang LW, Wu JP, Tsai MH, Wang HJ, Kuo YC, Yeh TK, Yang CS, Lin $P$ : Persistent tissue kinetics and redistribution of nanoparticles, quantum dot 705, in mice: ICP-MS quantitative assessment. Environ Health Perspect 2007, 115(9):1339-1343.

32. Cho WS, Cho M, Jeong J, Choi M, Cho HY, Han BS, Kim SH, Kim HO, Lim YT, Chung BH: Acute toxicity and pharmacokinetics of $13 \mathrm{~nm}$-sized PEGcoated gold nanoparticles. Toxicol Appl Pharmacol 2009, 236(1):16-24.

33. Wurster DE, Burke GM, Berg MJ, Veng-Pedersen P, Schottelius DD: Phenobarbital adsorption from simulated intestinal fluid, U.S.P., and simulated gastric fluid, U.S.P., by two activated charcoals. Pharm Res 1988, 5(3):183-186

34. Cho WS, Cho M, Jeong J, Choi M, Han BS, Shin HS, Hong J, Chung BH, Cho $\mathrm{MH}$ : Size-dependent tissue kinetics of PEG-coated gold nanoparticles. Toxicol Appl Pharmacol 2010, 245(1):116-123.

35. Derelanko MJ, Hollinger MA: Handbook of toxicology. 2nd edition. Boca Raton, FL: CRC Press; 2001.

doi:10.1186/1743-8977-10-9

Cite this article as: Cho et al:: Comparative absorption, distribution, and excretion of titanium dioxide and zinc oxide nanoparticles after repeated oral administration. Particle and Fibre Toxicology 2013 10:9.

\section{Submit your next manuscript to BioMed Central and take full advantage of:}

- Convenient online submission

- Thorough peer review

- No space constraints or color figure charges

- Immediate publication on acceptance

- Inclusion in PubMed, CAS, Scopus and Google Scholar

- Research which is freely available for redistribution 